\title{
Foreign Body Reaction with High Standard Uptake Value Level in 18-FDG PET/CT Mimicking Relapse in an 8-Year-Old Patient Diagnosed with Hodgkin Lymphoma: A Case Report
}

\author{
Derya Erdoğan ${ }^{1}$ Ceyhun Bozkurt² ${ }^{2}$ Özlem Özmen ${ }^{3}$ \\ ${ }^{1}$ Department of Pediatric Surgery, Dr Sami Ulus Maternity and \\ Children's Research and Training Hospital, Ankara, Turkey \\ 2 Department of Pediatric Oncology, Dr Sami Ulus Maternity and \\ Children's Research and Training Hospital, Ankara, Turkey \\ ${ }^{3}$ Department of Nuclear Medicine, Thoracic Surgery and Lung Disease \\ Training Hospital, Ankara, Turkey \\ ${ }^{4}$ Department of Pathology, Dr Sami Ulus Maternity and Children's \\ Research and Training Hospital, Ankara, Turkey
}

Eur J Pediatr Surg Rep 2013;1:60-62.

\author{
Esin Boduroglu ${ }^{4}$ Gürses Sahin ${ }^{2}$
}

\author{
Abstract \\ Keywords \\ - positron emission \\ tomography \\ - foreign body \\ - Hodgkin lymphoma \\ - lymph node \\ - childhood
}

Address for correspondence Derya Erdoğan, MD, Department of Pediatric Surgery, Dr Sami Ulus Maternity and Children's Research and Training Hospital, Babür caddesi No. 34, Ankara 06080, Turkey (e-mail: deryaerdo@yahoo.com).

\section{Introduction}

Early detection of the recurrence of the malign diseases after therapy is important for the surveillance of the patient. Various biochemical and imaging modalities are used for this purpose. We present a case of foreign body imitating recurrence in positron emission tomography and computed tomography (PET/CT) during the follow-up of a child who is cured with the diagnosis of Hodgkin Hodgkin lymphoma.

\section{Case Report}

The 8-year-old female patient had been followed-up for 3 years with the diagnosis of Hodgkin disease nodular sclerosing type. She had been diagnosed with cervical lymph node biopsy

received

February 8, 2013

accepted after revision

April 2, 2013

published online

May 9, 2013
3 years ago in another hospital and was sent to our pediatric oncology department for chemotherapy. She had six courses of ABVD (Adriblastina, Bleomycin [bleomycin sulfate], Vinblastine, dacarbazine) chemotherapy protocol and was accepted to be in remission since 2010 July. During the follow-up, a round, semimobile mass of approximately $20 \mathrm{~mm}$ in diameter was detected beneath the sternocleidomastoid muscle, at the onethird lower part of the left cervical region-the same location where the biopsy was performed earlier. Cervical ultrasonography was performed and this revealed a mass of $20 \mathrm{~mm}$ in diameter on the supraclavicular region, which had posterior acoustic shadow, and a dense content was found and it was evaluated as a calcified lymphadenopathy. Laboratory evaluations, lung graphy, and abdominal ultrasonography were all found to be normal. It was decided to follow her for another (c) 2013 Georg Thieme Verlag KG Stuttgart · New York
DOI http://dx.doi.org/ 10.1055/s-0033-1345278. ISSN 2194-7619. 


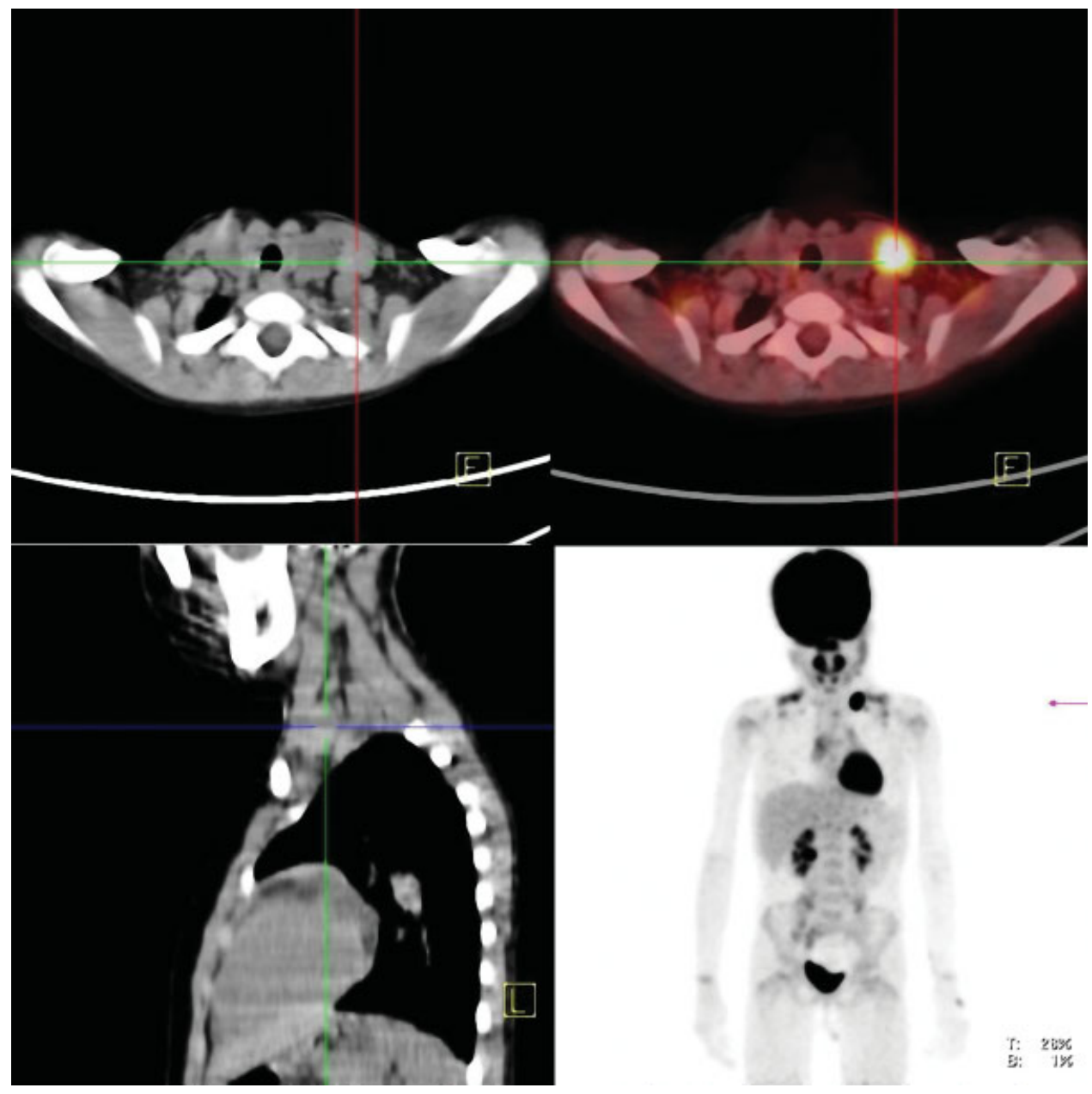

Fig. 1 Images showing a $2 \times 1.5 \mathrm{~cm}$ sized mass in the left supraclavicular region with increased metabolic activity (SUV $\max 9.09)$.

2 months and to repeat the cervical ultrasonography and to perform PET scintigraphy, if needed.

She was doing well 2 months later. On physical examination, the cervical lymphadenopathy was still detectable. Ultrasonography was performed. It was similar to the

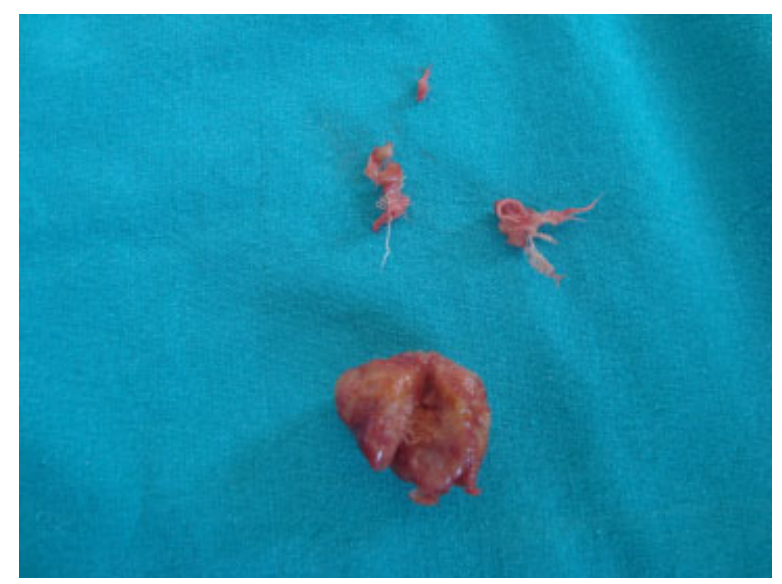

Fig. 2 Mass with sponge inside. previous one except size, and it was $25 \mathrm{~mm}$ in diameter now. PET/CT demonstrated focal, intense, and homogeneous FDG uptake in the $2-\mathrm{cm}$ mass at the left inferior cervical area with a maximum standard uptake value $\left(\mathrm{SUV}_{\max }\right)$ of 9.09. In addition, a few lymph nodes (biggest being $7 \mathrm{~mm}$ ) with undistinguishable FDG uptake were noticed next to the mentioned mass ( - Fig. 1 ). The earlier imaging findings, which had an appearance similar to that of lymph node involvement, led us to associate this with the previously existing malignancy.

The patient was consulted with the pediatric surgery department and was decided to perform excisional biopsy and pathological evaluation of the mass. During the operation, the previous incision was used and a mass beneath the sternocleidomastoid muscle was found. It was firm, semimobile, and had some adhesions to the surrounding tissues. During the dissection, a small portion was separated and some cotton material-like fiber was seen. It was excised totally ( - Fig. 2). In the macroscopic section, there was a sponge of 10 to $15 \mathrm{~mm}$ in diameter inside the mass and a tissue surrounding it. Pathology revealed epithelioid histiocytic reaction with foreign body-type multinuclear giant cells (hematoxylin-eosin $\times 100$ ) ( - Fig. 3 ). 


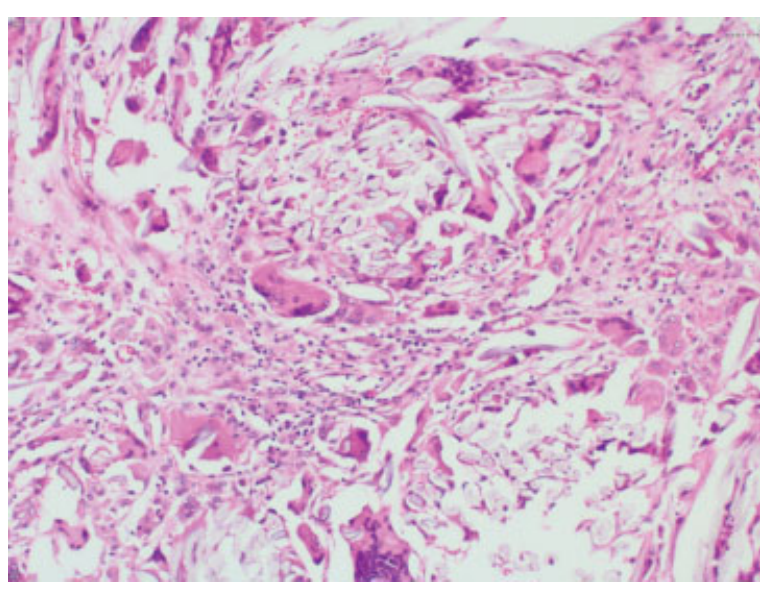

Fig. 3 Epithelioid histiocytic reaction with foreign body type multinuclear giant cells (hematoxylin-eosin $\times 100$ ).

\section{Discussion}

Although high-remission and disease-free ratio are obtained in the childhood Hodgkin Lymphoma disease, relapse or recurrence can occur in a small fraction of patients. The process-18FDG PET/CT - is normally used to differentiate benign from malignant disease as a result of difference in glucose metabolism. The 18-FDG PET/CT imaging has an important role for staging: evaluating the remission of the disease as well as to detect relapsing in Hodgkin lymphoma patients.

False-positive FDG uptake has been observed in various benign conditions, including inflammation, granulomatous disease, and abscess. Granuloma formation is a natural host reaction to foreign material. The high level of energy con- sumption was contributing functional activities. Tumor-like mass due to retained textile may show intense FDG uptake because of inflammatory changes such as granulomatous reaction. Retained textiles with foreign body granulomatous reaction can form mass-mimicking soft tissue tumors, which may cause diagnostic, clinical, and medicolegal problems as in our case. ${ }^{1,2}$

False-positive FDG uptake is well recognized in granulomatous processes and as such, textile granulomas may be mistaken for nodal disease in patients with Hodgkin lymphoma on FDG PET/CT.

We want to point out that when the PET/CT shows high accumulation of 18-FDG in Hodgkin lymphoma patients despite the patient's clinical stability and normal laboratory pathological findings, false positivity of PET/CT in conditions such as follicular hyperplasia, brown fat tissue, and rarely foreign body reaction in the operation localization should be kept in mind.

\section{Conflict of Interest}

None

\section{References}

1 Kim SW, Shin HC, Kim IY, Baek MJ, Cho HD. Foreign body granulomas simulating recurrent tumors in patients following colorectal surgery for carcinoma: a report of two cases. Korean J Radiol 2009;10(3):313-318

2 Miyake KK, Nakamoto Y, Mikami Y, et al. F-18 FDG PET of foreign body granuloma: pathologic correlation with imaging features in 3 cases. Clin Nucl Med 2010;35(11):853-857 